\title{
ROLE OF NUDGING IN SELECT GOALS OF SUSTAINABLE DEVELOPMENT
}

\author{
Ms. Neha Sawant \\ Dr. Archana Fulwari
}

\begin{abstract}
Humankind has made tremendous progress in the 21st century. However, this progress has come at increased costs in terms of depletion of natural resources and environmental degradation. In response to this there is a growing concern across countries to adopt and achieve the goals of sustainable development. However, it is a challenging task as it requires changes in human psychology and practices, particularly, apathy and lethargy. It requires sensitization and influencing of the perception of human beings, which in turn calls for much effort. It is necessary to go beyond traditional approaches of laws and rules that involve penalties and compulsions with huge costs of implementation and compliance tracking. There is need to incorporate innovative ways of dealing with the issue. The Nudge theory offers one such alternative that can complement the traditional approaches. In this context, the present examined various steps taken by governments in India and other countries to incorporate nudging in the efforts to achieve goals of sustainable development. An examination of the effectiveness of nudge in the form of mid-day meal scheme in government schools in India was also undertaken. Preliminary analysis revealed favorable effect of the nudge in improving enrolment and attendance in primary schools.
\end{abstract}

Keywords: Sustainable Development Goals, Nudge Theory, Mid-day Meal Scheme

Human beings have been exploiting nature for satisfying their greed much beyond their need. Unabashed use of natural resources for the uncontrolled urge for progress causes imbalance and disharmony in nature and raises serious doubts on the sustainability of such growth. The consequences of human activities are alarming 
Towards Excellence: An Indexed, Refereed \& Peer Reviewed Journal of Higher Education / Ms. Neha

Sawant \& Dr. Archana Fulwari/ Page 97-110

and call for immediate action. With a view to achieving growth with environmental sustainability, the United Nations (UN) laid down the Millennium Development Goals (MDGs) in the year 2000 which were followed by the Sustainable Development Goals (SDGs) set in 2015.

Both developed and developing countries are trying to achieve these goals by policy formulations and appropriate interventions. India too, has embarked on the path to achieve these goals with the help of various plans, policies and programmes. However, achieving these goals is not an easy task as it often requires change in human behaviour and attitude. The traditional measures include penalty on violation of norms, and incentives to induce certain actions of the stakeholders. However, these steps do not ensure complete success. Also it requires huge amounts of money to be spent. The root cause behind limited success of such measures often lies in the absence of behavioural changes in human beings that need to accompany policy interventions so as to bring real and sustainable transformations. This has led to governments now turning to behavioural insights that can be built into the framing of policies and programmes. Governments across countries are attempting to derive insights from behavioural sciences. "Behavioural sciences, drawing on insights from cognitive and social psychology, stress the less rational nature of the human species and highlight the importance of behavioural biases and the decision context - the environment in which individuals make choices" (Lehner, Mont and Heiskanen, 2015). Nudge is one such concept that combines the fields of behavioural economics, political theory and behavioural sciences.

There are several studies that have analyzed the use of nudge in relation to the SDGs, to inquire if nudging can bring about desired changes in human behaviour. Johnson and Goldstein (2003) and Shaffer (2017), for instance, have explored the effectiveness of using the typical 'Status Quo Bias' of people to continue with 'Default Choices' rather than go for a deliberate choice of other alternatives. While the former examines nudge in relation to issues of organ donation, the latter examines it in the context of promoting healthy eating habits, wherein, the nudge intervention not only aimed at promoting healthy eating but in the process sought to reduce overutilization of healthcare and the cost of health. Both studies, carried out in the United States, report a favourable impact of the default choice setting. Another 
Towards Excellence: An Indexed, Refereed \& Peer Reviewed Journal of Higher Education / Ms. Neha

Sawant \& Dr. Archana Fulwari/ Page 97-110

study, Hansen (2016), finds that nudge in the form of 'Unit Bias' - making bite sized healthy food options available - was successful in inducing people into healthy eating.

Lehner, Mont and Heiskanen (2015) examine nudging as a potential policy tool that can be used by government for bringing about behavioural changes in individuals so as to solve problems of climate change, environmental impact and resource efficiency. They discuss four types of tools that nudge comprises, namely, simplification and framing of information, changes to physical environment, change to the default policy and use of social norms in the context of three environmentally relevant consumption domain, viz. housing, transport and food and drink. The study provides several evidences of effectiveness of each tool in the three consumption domains.

Singh and Gupta (2015) have analyzed the impact of mid-day meal scheme (MDMS) on various aspects like enrolment, attendance, drop-out and retention of primary school children in rural and urban areas of Uttar Pradesh. A similar study has been carried out by Sofi (2017) for Pulwama and Srinagar. Both studies find positive impact of the MDMS in improving enrolment and attendance in primary school as well as fall in drop-outs rates. Along with the favourable effect from education point of view the MDMS also helps in achieving other SDGs such as zero hunger and good health and wellbeing.

Another study, Sinha (2019), builds linkages of MDMS with factors like food security, productivity, cognitive ability, etc. Apart from impact on attendance and enrolment, the study also examines the social impact of the scheme. Using correlation and regression technique, the study finds the MDMS to be more effective in rural areas. The positive social impact was found in terms of reduction in gender disparity as more girls were encouraged for enrolment.

Sharma, et.al. (2017) assert the significance of a Nudge Unit in India. The study discusses instances where nudge is used, such as, text messages or mails promoting voters to vote, putting images of religious figures and symbols at public places where people tend to urinate, encouragement to teachers and students to 
Towards Excellence: An Indexed, Refereed \& Peer Reviewed Journal of Higher Education / Ms. Neha

Sawant \& Dr. Archana Fulwari/ Page 97-110

promote quality in teaching, etc. The study finds that with the use of some kind of nudge as a tool, people's behaviour could be influenced in a positive way.

The 2017 UNEP Report related to Global Action for Sustainable Consumption and Production asserts that behavioural sciences can be successfully coupled with policy to bring the desired effects in a cost-effective manner. It emphasises on behaviourally informed policy tools that can sensitize consumers about the costs and benefits their preferences exert on resource utilization and thereby increase the efficacy of government interventions.

Smets and Lievens (2018) have stressed on the role of nudging in bringing behavioural changes in industry, government and citizens so that a circular economy which entails integration of economic activities and environmental sustainability can be encouraged in response to growing urban demand. They have emphasized the role of technologies such as the Internet of Things on account of which more real time data on actual human behaviour has become available. This enables the formulation of personalized nudges for greater effectiveness and for scalability and speed of the nudges. Use of technologies also helps in evaluating the effectiveness of the nudges.

Lundstrom (2018) has studied the effectiveness of nudging in the form of 'Default Option' and of adding a product for 'Attraction Effect', in promoting environment friendly purchases of electronic products. The study found that nudging in the form of attraction effect was more effective in inducing environment friendly buying behaviour compared to default choice nudge. Bolos, et.al. (2019) have studied consumer choice and causes of food waste in supermarkets in United States and Europe. The study uses three nudge interventions, namely, attention based intervention, interest based intervention and action based intervention. The study examines the role of these three nudges to encourage consumption of healthy food options.

\section{Objectives of the Study and Research Methodology}

In view of the review of literature, the present study seeks to identify the use of nudges in achieving the SDGs. The objectives of study are as follows: 
- To provide an understanding the concept of nudge

- To identify the role of nudge in select SDGs

- To examine the effectiveness of nudge in the form of Mid-day Meal scheme

The study is descriptive and exploratory in nature. It identifies practices and experiments that involve nudges used in targeting the goals of sustainable development, which have been sourced from websites like the World Economic Forum and news articles. Further, the study analyses one scheme introduced by state governments in India, the mid-day meal scheme (MDMS), as a nudge to encourage school enrolment. For this the study examines the trends in Gross Enrolment Ratio and state wise attendance in schools in relation to the MDMS. The data related to attendance in schools has been taken from the Evaluation Report of the 'Education for All' movement of the government which is based on a sample survey carried for the year 2010.

\section{The Concept of Nudging}

Behavioural economics is a branch of behavioural science which studies human psychology in understanding and explaining economic decision making. It is a combination of psychology, economics and management. In traditional economic theories, human beings are assumed to be rational in decision making. But many economists criticised this premise on the grounds that human beings are also affected by emotional, cultural, and environmental situations so that they often make decision that are far from rational and are less than optimal. Later developments in behavioural economics attempted to incorporate the irregularities and behaviour peculiarities of human beings in explaining how economic decision making problems were solved. Since the decisions are often based on irrational behaviour the choices made are not always beneficial to the decision maker or to the society at large. In this context, a new theory propounded under the branch of behavioural economics is the Nudge Theory by Richard Thaler and Cass Sunstein in 2008. In their book, "Nudge: Improving Decisions about Health, Wealth, and Happiness" Thaler and Sunstein have analysed the peculiarities of human beings and suggested how nudging can be used to act upon these peculiarities. They defined nudge as "any aspect of choice architecture that alters people's behaviour in a predictable way 
without forbidding any options or significantly changing their economic incentives." Thaler and Sunstein differ from other behavioural economists in that they demonstrate how a nudge can used to design choices in a way that ultimately fulfil the objectives of governments and businesses. This is known as choice architecture - designing choices in a way that induces decisions for the betterment of society. People have the liberty to choose the options as per their wish but at the same it preserves the government objectives of driving people into making the right choice. Thaler and Sunstein called this as "Libertarian Paternalism".

While nudge has been practiced by businesses since long, it is its application in the area of government policy that has impressed upon the countries. The US, the UK, Germany, France, Canada, Denmark, the Netherlands, Australia, Singapore and Peru are among the pioneers in the use of behavioural insights in policy making (World Bank Report on Behavioural Science around the World). In India too behavioural insights are being increasingly used in policy making. This paper links select SDGs and nudges that are used by governments of countries across the world.

\section{Nudges and the Goals of Sustainable Development}

Each country faces a different set of problems related to culture, environment, social setup, etc., which influence behaviours, and have varying degrees of awareness and sensitivities among its people. Various tools and policies are therefore required that can internalize the behavioural aspects of human beings in their responses to the policy interventions. The study points out various nudges used in targeting select SDGs, namely, Cleanliness, Climate Action, Zero Hunger and Education.

\section{- SDG: Climate Action and Zero Hunger}

Several practices can be exemplified as nudges to influence human behaviour in order to achieve the SDGs aiming at environmental protection. One such effort is the first Garbage Café in Ambikapur, Chattisgarh where people bring plastic waste and get food in return. This is a great nudge to people to give proper channel to plastic waste. Thus, government can target three different goals of SDGs, i.e. Cleanliness, Climate Action and Zero Hunger. The same move has also been replicated at Dahod, Gujarat at Dahod Café. In exchange of plastic waste, they serve tea and snacks. In Philippines a similar experiment is being conducted where people 
exchange plastic over rice in the ratio of 2:1. Similarly, some countries place vending machines that dispense vouchers in exchange for empty plastic water bottles. These small but great efforts demonstrate how small actions can play important role in sensitizing people towards cleanliness and environmental issues. These steps do not involve much cost, and create value for the plastic waste, which ultimately makes for the betterment of the society at large.

\section{- SDG: Climate Action, Education and Zero hunger}

Nudging is also found to be applied to encourage education among the less privileged. A school in Assam, India, has started accepting plastic waste as school fees. This is a great effort towards cleanliness and environmental protection as well as to enhance enrolment and continuation in education. Also, Mid-day Meal Programme comprising of serving healthy meals to children at the government schools aims at enhancing the achievement of the several goals together, namely, Zero Hunger, Health and Education. This motivates parents to enrol their children in school. The problem of malnutrition or food deficiency among children can be addressed through this programme.

Another practice is that aimed at discouraging food wastage being undertaken by some restaurants such as those in Chennai, India. It involves charging a penalty of Rs.100 per 10 grams of food wasted by guests and the penalty amount is dropped into a donation box. While the experiment involves cash penalty, it can be considered as a nudge as it induced people to place smaller orders in the first place and thereby avoid food wastage as well as payment of the penalty. The experiment was successful as measured by the drop in the number of waste containers collected daily from 14 to 2 . The restaurants also benefitted in terms of improved image among the people and continued to be patronized by the guests.

\section{- SDG: Climate Action and Life Below Water}

Plastic waste littered at public places and at sea-shores and rivers affects lives of stray animals and marine creatures. NGOs and governments are creating 
Towards Excellence: An Indexed, Refereed \& Peer Reviewed Journal of Higher Education / Ms. Neha

Sawant \& Dr. Archana Fulwari/ Page 97-110

awareness to keep sea shore clean and plastic free. In this context, Jessica Nguyen (2019) in an article in the Vietnam Economic Times mentions about the Goby fish fish shaped trash bins - placed at the Da Nang Beach, Indonesia for plastic disposal. While it is a great attraction for tourists, it gives two messages. One, as the plastic waste gets collected in the fish structure put up at the sea shore, it creates the visual of marine animals inadvertently swallowing the waste, and second, it induces tourists to throw waste in the trash bins rather than litter it around. While the first message creates awareness how the waste affects the marine life, the second message creates awareness towards cleanliness. Similar practices have been started at other places too, such as, at the Malpe beach, Mangalore, India.

\section{- SDG: Clean Water and Sanitation, Good Health and Well being}

To make India open-defection free is among the important objectives of Government of India. To discourage people from urinating in public places, apart from measures such as fines and putting images of deities on the walls, the Karnataka government came up with the idea of putting mirrors on the wall with a QR code that can be scanned by people to locate nearby toilets. A mirror on the wall would shame people and nudge people towards hygiene.

\section{- SDG: Good Health and Well being}

Another SDG related issue is the harmful consumption habits prevalent among youngsters leading to health problems. There are instances where cigarettes are consumed and littered by people. Selagea et.al. (2016) conducted an experiment in Lucian Blaga's University of Sibiu, Romania in this regard. The smoking area of the University where students frequently smoked was chosen for nudge intervention. A transparent box with two sections was placed as cigarette butt bin in the smoking area. A question that was interesting to the youngsters was put on the box with students having to answer in Yes or No by throwing the cigarette butts in either of the two sections representing the yes and no answers. The nudge worked in the following manner. The questions made it interesting for students to respond, thereby, attracting them to throw the butts in the boxes rather than litter them around. Secondly, the transparent boxes with cigarette butts glaringly displayed the amount 
of smoking that was being done by the students, indirectly sensitizing them towards the harm they were causing to their health. The experiment found success in terms of reduction in the number of butts over the observation period.

\section{Mid-day Meal Scheme as a Nudge}

In 1995 the mid-day meal scheme was launched as the National Programme of Nutritional Support to Primary Education sponsored by the central government. In year 2001, the Supreme Court mandated the mid-day meal programme for all government and government aided schools with the objective to provide healthy and nutritious food to school children. It helps in achieving the twin objectives of reducing malnutrition and encouraging enrolment and attendance in schools.

The MDMS can be construed as a nudge to encourage children to enrol in schools by providing hygienic and health meals at noon to school children. The present study examines trends in gross enrolment ratio and attendance in schools across select states of India to enquire if the MDMs are an effective nudge.

\section{Gross Enrolment Rate (GER)}

The Gross Enrolment Ratio considers all students enrolled in a given level of education regardless of their age as a proportion to the population of the age group which officially corresponds to the given level of education. Fig. 1 depicts the trend in the GER over the 46-year period from 1971 to 2017.

Fig.1: Gross Enrolment Ratio (Primary Schools) - India

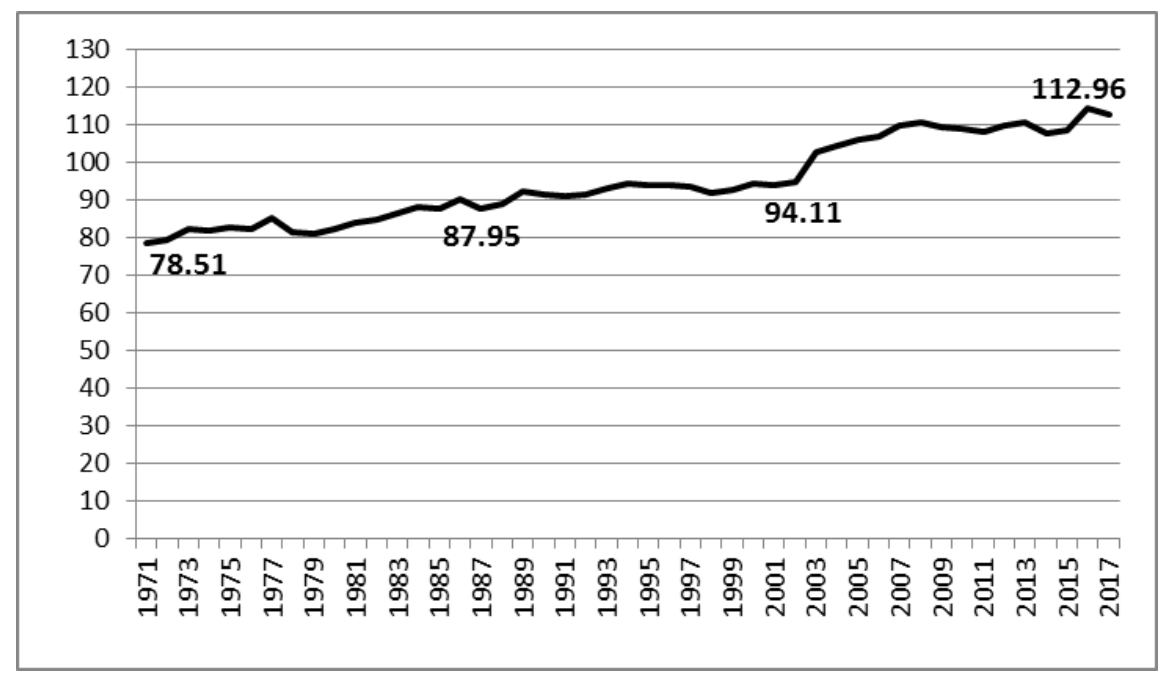


Source: World Bank

The figure shows increasing trend in the GER growing at a compound annual growth rate of 0.79 percent. However, since 2001, when the Supreme Court made the midday meal mandatory, the CAGR increased to 1.15 percent over the 16 year period from 2001 to 2017. Over the 16 years prior to the SC mandate, that is, from 1985 to 2001, the CAGR in GER is a meagre 0.42 percent. For the entire study period prior to 2001 , the CAGR is found to be 0.61 percent. This analysis clearly shows that the nudge in the form of free mid-day meals provided in primary schools has been effective in inducing more children to get enrolled.

\section{Attendance at Schools serving MDMs in Select States}

To examine the effectiveness of MDM scheme, the paper examines the data on attendance in schools providing MDMs for different states. Table 1 shows categories of states based on percentage of schools covered under MDMS and relates them to attendance rates ranging from above $75 \%, 45-75 \%$ and below $45 \%$ as depicted in Fig. 2.

Table 1: Category of States as per Coverage of Schools under MDMS

\begin{tabular}{|c|c|c|c|}
\hline $\begin{array}{c}\text { State Category as per } \\
\% \text { of School covered } \\
\text { under MDMS }\end{array}$ & $\begin{array}{c}\text { Percentage of } \\
\text { Schools under } \\
\text { MDMS }\end{array}$ & $\begin{array}{c}\text { Sr. No. } \\
\text { of } \\
\text { States }\end{array}$ & Names of States \\
\hline High coverage & $100 \%$ & 1 to 5 & $\begin{array}{c}\text { AP, Rajasthan, TN, } \\
\text { WB, Chandigarh }\end{array}$ \\
\hline Medium coverage & $80-100 \%$ & 6 to 7 & MP, UP \\
\hline Low coverage & $60-70 \%$ & 8 to 11 & $\begin{array}{c}\text { Bihar, Assam, } \\
\text { Haryana, HP }\end{array}$ \\
\hline
\end{tabular}

Fig. 2 Attendance Rates and Proportion of Schools under MDM Scheme in Select States of 
India

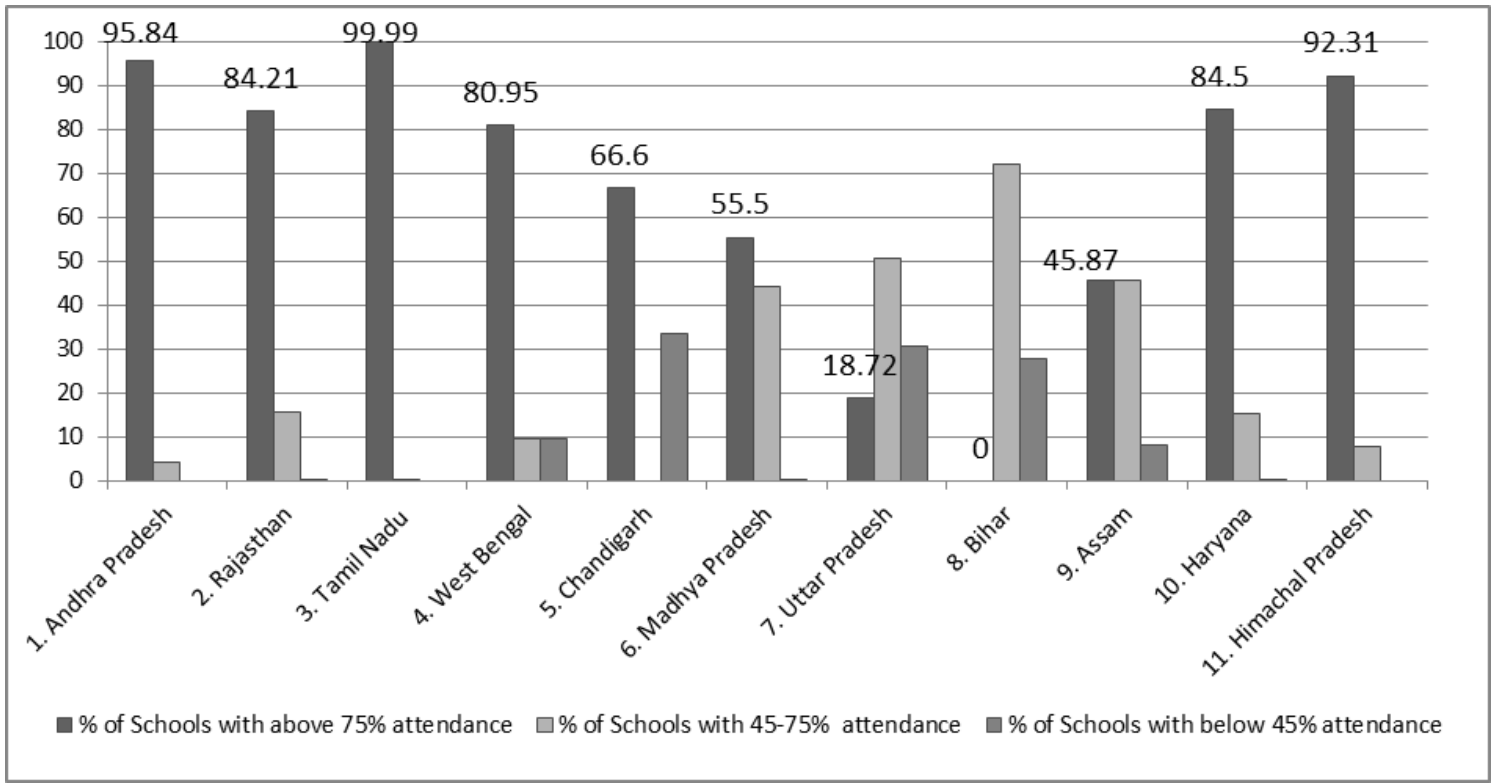

Source: Evaluation Report on 'Sarva Shiksha Abhiyan', data.gov.in

Very interesting revelations emerge from Fig.2. States having 100 percent schools under the MDMS have very high proportion of schools with attendance above 75 percent. Within this category of states, barring Chandigarh, all other states have 80 to 95 percent of schools having attendance more than 75 percent. The National Programme of MDM in schools in Andhra Pradesh shows that the retention rates have increased from $90.32 \%$ in $2016-17$ to 92.38 in $2017-18$ in primary schools. Also the drop-out rates have reduced from 2.15 in $2016-17$ to zero in $2017-18$.

In two states, Madhya Pradesh and Uttar Pradesh which have more than 80 percent schools with MDMS, much lower percentage of schools are found to have attendance above 75 percent. The third category of states (Sr. No. 8 to 11) has only 60 to 70 percent schools covered under the MDM scheme. These states produce a mixed result with rates of attendance above 75 percent ranging from zero to 92 percent of schools, except the state of Bihar which has no schools with attendance rate above 75 percent.

From the analysis it may be inferred that MDMS as a nudge has been quite effective in improving attendance of students in school. The analysis, however, also reveals that MDMS is not strong enough a nudge, particularly, in states with higher rates of poverty. Irrespective of coverage of schools under the MDM scheme, those states 
which have higher than average poverty rates of India are also the states with poor attendance in. These include Bihar, MP, UP and Assam. This implies that higher levels of poverty are deterrents to school enrolment. More in-depth research is required to substantiate the inference. Nonetheless, it shows that policy makers need to adopt a more holistic approach in policy formulations considering the higher levels of poverty so that there is strong motivation among parents to send their wards to school.

Nudge is a unique concept which seeks to invoke favourable changes in human behaviour for the betterment of society. The SDGs are typically goals which require attitudinal and behavioural changes in human beings. Therefore, along with traditional tools of taxes, subsidies, fines and sanctions, nudging very well suits the efforts to achieve these goals. Nudge is a concept which consciously or subconsciously attracts people and reinforces behavioural changes more effectively. Therefore, governments in particular, are planning the use of nudging directly or designing programme and movements which are characteristic of nudges. While traditional approach of penalties, taxes and subsidies have their usefulness, the design of these measures to incorporate behaviour insights and including nudge elements into it can go a long way in improving the effectiveness of government measures towards the achievement of the goals of sustainable development. Often the nudge interventions may be scattered attempts and limited in scale and time. Therefore, continuous efforts to innovate new forms of nudges are required for inducing behavioural shifts. 
Towards Excellence: An Indexed, Refereed \& Peer Reviewed Journal of Higher Education / Ms. Neha

Sawant \& Dr. Archana Fulwari/ Page 97-110

\section{Works Cited}

Bolos, L.A., Lagerkvist, C. J., and Nayga, R. (2019). Consumer Choice and Food Waste: Can Nudging Help? Agricultural and Applied Economics Association, 34(1). https://www.researchgate.net/publication/331207943

Hansen, P.G., Skov, K.L., Skov, L.R., Jespersen, A. M., and Schmidt, K. (2015).

Apples vs. Brownies: A Field Experiment in Rearranging Conference Snacking

Buffets to Reduce Short-Term Energy. Journal of Foodservice Business Research, 19.

https://doi.org/10.1080/15378020.2016.1129227

Johnson, E. J. and Goldstein, D. (2003). Do Defaults Save Lives? 302 SCIENCE 1338. https://doi.org/10.1126/science.1091721

Lehner, M., Mont, O., and Heiskanen, E. (2015). Nudging - A Promising Tool for Sustainable Consumption Behaviour? Journal of Cleaner Production. 134, Part A: 166-177. https://www.researchgate.net/publication/287406587_Nudging__A_promising_tool_for_sustainable_consumption_behaviour. https://doi.org/10.1016/j.jclepro.2015.11.086

Lundström, H. (2018). Sustainable Behaviour through Nudging? An Experimental Study on Nudging, Climate Change Denial and Political Orientation. Uppsala University Publications, p. 28, diva2:1281473

Nguyen, J. (2019, May 13). "Goby fish bins to 'eat' plastic waste on Da Nang beach".

Retrieved from http://vneconomictimes.com/article/society/goby-fish-bins-to-eatplastic-waste-on-da-nang-beach.

Selagea, V. I., Simeanu, C. M., Stancu, E. A., Marcu, M. G., and Iordănescu, E.

(2016). Nudge: Influencing Smokers' Behavior of Cigarette Butts Throwing.

Psychology of Political and Economic Self-Constitution, Proceedings of the IV International Scientific and Practical Seminar.

Shaffer, V. A. (2017). Nudges for Health Policy: Effectiveness and Limitation. Missouri Law Review, 82(3).

Sharma, N., Arora, P., and Srivastava, P. (2017). Nudge Units in India: A Fresh Route to Welfare.

https://www.researchgate.net/publication/317821210_Nudge_Units_in_India_A_F resh_Route_to_Welfare 
Singh, S., and Gupta, N. (2015). Impact of Mid Day Meal on Enrolment, Attendance and Retention of Primary School Children. International Journal of Science and Research, 4(2).

Sinha, N. (2019). Mid Day Meals: A Detailed Study of Indian States. International Journal of Research and Analytical Reviews, 6(2).

Smets, A., and Leivens, B. (2018). Nudging Sustainable Behaviour: The Use of Data-driven Nudges to Support a Circular Economy in Smart Cities. https://www.researchgate.net/publication/327797219

Sofi, M., A. (2017). Impact of Mid-day Meal Scheme on Enrolment and Dropout Rate of Students at Primary Level. International Journal of Advanced Education and Research, 2(4): 91-92.

United Nations Environment Programme (2017). Consuming Differently, Consuming Sustainably: Behavioural Insights for Policymaking.

\section{Ms. Neha Sawant \\ Research Scholar Department of Business Economics \\ Faculty of Commerce}

The Maharaja Sayajirao University of Baroda, Vadodara

E-mail: nehasawant1429@gmail.com

\&

Dr. Archana Fulwari

Assistant Professor

Department of Business Economics

Faculty of Commerce

The Maharaja Sayajirao University of Baroda, Vadodara

Email: archanafulwari@gmail.com 